\title{
Effectiveness and safety of cyclosporin A therapy in steroid dependent nephrotic syndrome in childhood
}

\author{
A H H M Jayaweera ${ }^{1}$, A S Abeyagunawardena ${ }^{2}$ \\ Sri Lanka Journal of Child Health 2012; 41(4): 176-179
}

\begin{abstract}
Objective: To analyse the effectiveness and safety of cyclosporin A (CsA) in the treatment of steroid dependent nephrotic syndrome (SDNS) in childhood.
\end{abstract}

Design: Prospective descriptive study

Setting: Nephrotic Syndrome Clinic, Teaching Hospital Peradeniya, Sri Lanka

Method: Children with SDNS who had normal renal function, relapsed while receiving over $1 \mathrm{mg} / \mathrm{kg}$ prednisolone on alternate days and who had received at least one course of cyclophosphamide were recruited to the study over a period of 5 years. They were treated with $\mathrm{CsA} 3-5 \mathrm{mg} / \mathrm{kg} /$ day orally with a tapering dose of alternate day prednisolone. Statistical analysis was performed using paired t-test.

Results: Over 5 years, 48 children who satisfied the inclusion criteria were recruited. CsA therapy was discontinued in two patients who had evidence of nephrotoxicity within 6 months of therapy. Forty six patients completed the study. Thirty one were male. The maintenance dose of prednisolone was tapered at least by $50 \%$ at 6 months of therapy in $38(83 \%)$ patients. At the completion of 6 months of therapy, the mean serum cholesterol decreased from 396.96 $\mathrm{mg} / \mathrm{dl}$ to $269.5 \mathrm{mg} / \mathrm{dl}(\mathrm{p}<0.01)$ and the mean serum albumin increased from $21.1 \mathrm{mg} / \mathrm{dl}$ to $33.5 \mathrm{mg} / \mathrm{dl}$ $(\mathrm{p}<0.01)$. Hypertension was seen in $26(57 \%)$ patients and hirsutism in $37(80 \%)$. All patients had normal liver enzymes and opportunistic infections were not encountered.

Conclusions: CsA treatment in combination with low-dose prednisolone is highly effective in maintaining complete remission in difficult SDNS in childhood. Reversible nephrotoxicity was seen in $4 \%$ of patients, hypertension in $57 \%$ and hirsutism in $80 \%$.

${ }^{1}$ Lecturer in Paediatrics, ${ }^{2}$ Professor in Paediatrics, Department of Paediatrics, University of Peradeniya

(Received on 5 December 2011: Accepted after revision on 27 January 2012)
(Key words: Nephrotic syndrome; steroid dependence; cyclosporin A; relapse)

\section{Introduction}

Children with steroid dependent nephrotic syndrome (SDNS) usually experience steroid toxicity as they need to be maintained on steroids for prolonged periods ${ }^{1}$. Alkylating agents like cyclophosphamide and chlorambucil have been used as adjuncts to corticosteroid therapy for sustaining remission in patients with frequently relapsing nephrotic syndrome. Although efficacy of these drugs is well established in patients without steroid dependence, its effects have been rather variable in steroid dependent patients $^{2}$. Moreover, the potential side effects, particularly risks of opportunistic infections, sterility in men and development of future malignancies have limited their use in $\mathrm{SDNS}^{3,4}$.

Idiopathic nephrotic syndrome (INS) is considered an immunological disorder, a disorder of $\mathrm{T}$ cell function. It is now believed that a disturbance in the Th1 and Th2 immune mechanisms, mediated by cytokines and lymphokines, are responsible in both generation of the disease and its relapse ${ }^{5}$. In 1985, some reasoned that the postulated immunologic mechanism of INS (i.e. secretion of a cationising lymphokine by $\mathrm{T}$ lymphocytes resulting in proteinuria) would be responsive to treatment with cyclosporin A (CsA), given the mode of action of this new immunosuppressive agent ${ }^{6,7}$.

There is consistent evidence, from both experimental and human studies, that the highly lipophilic CsA molecule diminishes or abolishes proteinuria by two mechanisms $^{8}$. The first is its immunosuppressive action, in which CsA prevents the release of interleukin-2 and interferon and possibly other lymphokines from activated $\mathrm{T}$ cells, suppressing glomerular permeability ${ }^{9}$. The second mechanism is a direct action on the selectivity of the glomerular basement membrane, especially on the electromechanical barrier which repulses the anionic albumin molecules ${ }^{10-12}$.

CsA therapy is well recognised regarding its steroid sparing effect in steroid dependant patients and is 
responsible for maintaining remission in more than $75 \%$ of patients with SDNS even after discontinuation of steroids ${ }^{1,13,14}$. Furthermore, it has been shown to be effective in inducing remission in steroid resistant INS ${ }^{15,16}$. CsA is associated with a plethora of side effects such as hypertension, nephrotoxicity hypertrichosis, gum hyperplasia, gastrointestinal disturbances and tremor ${ }^{17,18}$. The effects of CsA therapy on Sri Lankan children have not been documented in the published literature.

\section{Objective}

To analyse the effectiveness and safety of CsA in the treatment of SDNS in childhood

\section{Patients and Methods}

Sequential children presenting with SDNS to the Nephrotic Syndrome Clinic at Teaching Hospital, Peradeniya, a tertiary referral centre in Sri Lanka, from 2004, who fulfilled the following inclusion criteria were enrolled: Two or more consecutive relapses while receiving over $1 \mathrm{mg} / \mathrm{kg}$ of prednisolone on alternate days, with normal renal function and who had received at least one course of cyclophosphamide and had a renal biopsy. They were treated with CsA $3-5 \mathrm{mg} / \mathrm{kg} /$ day aiming to achieve a 12 hour trough level between 75-100ng/ml. All patients were requested to test and record the urinary protein excretion daily and were reviewed on a monthly basis. On each review the patients were carefully examined for side-effects of CsA such as hirsutism, hypertension, gingival hypertrophy and opportunistic infections. The biochemical evaluation of the nephrotic state, liver and renal functions were made by serial assessment of urinary protein excretion, serum albumin, serum cholesterol, serum alanine transaminase and serum creatinine performed at 3 monthly intervals. Primary end points of the study were to analyse the rise of serum albumin, reduction of serum cholesterol and reduction of maintenance dose of prednisolone at 6 months of therapy. Additionally, in order to evaluate the safety profile of CsA therapy analysis was made on the side effects of CsA. Statistical analysis was performed using paired t-test. Criteria for diagnosis of nephrotic syndrome, remission, relapse, and steroid dependence, were as per definitions used by the International Study of Kidney Disease in Children $^{19,20}$.

\section{Results}

Over a period of 5 years 48 children who satisfied the inclusion criteria were recruited to the study. CsA therapy was discontinued in two patients who had evidence of nephrotoxicity within 6 months of therapy and they were excluded from the analysis for effectiveness. Of the remaining 46 thirty one (70\%) were boys. The ages of the patients ranged from 2 years to 12.5 years with a mean of 8.9 years. Of the 46 children who completed 6 months of CsA therapy, pre-CsA histology showed focal segmental glomerulosclerosis (FSGS) in 18 (39.2\%), diffuse mesangial proliferation (DMP) in $8(17.3 \%)$, and minimal change disease in $20(43.5 \%)$. The mean duration of therapy was 1.77 years (6 months -4 years). The maintenance dose of prednisolone was tapered by at least $50 \%$ at 6 months of therapy in 38 $(82.5 \%)$ patients. At the completion of 6 months of therapy the mean serum protein increased from 44.5 $\mathrm{mg} / \mathrm{dl}$ to $58.75 \mathrm{mg} / \mathrm{dl}(\mathrm{p}<0.05)$, the mean serum albumin increased from $21.1 \mathrm{mg} / \mathrm{dl}$ to $33.5 \mathrm{mg} / \mathrm{dl}$ $(\mathrm{p}<0.01)$ and the mean serum cholesterol decreased from $396.96 \mathrm{mg} / \mathrm{dl}$ to $269.5 \mathrm{mg} / \mathrm{dl}(\mathrm{p}<0.01)$. The subgroup analysis according to the different histological types did not reveal a significant difference in the response rates.

Hypertension needing antihypertensive treatment was seen in $26(57 \%)$ of the 46 patients. Two (4\%) patients had significant elevations of serum creatinine needing discontinuation of treatment. Significant hirsutism was noted in $37(80 \%)$ patients. All patients had normal liver enzymes and opportunistic infections were not encountered in this cohort of patients.

\section{Discussion}

A cardinal feature of INS is the tendency to relapse. Relapses generally respond to steroids much better than the initial episode. Unlike the initial treatment regimen, more intensive treatment of relapses with higher doses or longer duration of prednisolone has little or no effect on the subsequent relapse rate. Children with a frequently relapsing disease or steroid dependent disease ideally need individualised treatment. Although there is no data on the merits of long-term maintenance prednisolone as opposed to repeated standard relapse treatment, most favour the former approach ${ }^{19,21}$. The dose of prednisolone should be titrated to the lowest that is sufficient to maintain remission in order to minimise steroid toxicity. Most school age children can tolerate 0.5$0.6 \mathrm{mg} / \mathrm{kg} /$ body weight on alternate days, while preschool children may tolerate up to $1 \mathrm{mg} / \mathrm{kg} / \mathrm{body}$ weight on alternate days. The duration of alternate day prednisolone therapy should be for a minimum of 3-6 months, although a selected group of children may benefit from longer duration of treatment ${ }^{21}$. 
Steroid toxicity is of major concern to children with INS and their families. There is a positive correlation between toxicity and cumulative dose of steroids in children with SSNS $^{21}$. Obesity, hirsutism, hypertension, psychological and behavioural disturbances are usually reversible after cessation of steroid therapy. However, striae and cataracts are irreversible. Moreover, prolonged steroid therapy is associated with significant growth impairment ${ }^{2}$.

In SDNS CsA is generally reserved for children who demonstrate steroid dependence following a course of cyclophosphamide. However CsA is now increasingly used in preference to cyclophosphamide in children approaching puberty, especially in boys, who are more vulnerable to gonadal toxicity and in whom the disease may be nearing the end of its natural history, obviating the need for prolonged immunosuppression. The usual dose of CsA is 3$5 \mathrm{mg} / \mathrm{kg} /$ day to achieve a 12 hour trough blood level of $50-150 \mathrm{ng} / \mathrm{ml}$, usually for up to a year. The optimal duration of CsA therapy, however, is unclear. Unlike cyclophosphamide, the relapse rates are high when the drug is discontinued ${ }^{19}$. Sustained remissions have been achieved with continuous CsA therapy for 5 years ${ }^{19}$ but the prolonged use of CsA necessitates regular and frequent monitoring of blood levels at least 3 monthly when stable, and regular estimation of glomerular filtration rate because of its potential nephrotoxicity. Moreover, prolonged therapy with CsA may be associated with a long-term risk of lymphoma ${ }^{19,22}$ and thus should be considered only for selected patients with SSNS who are difficult to control.

Most of the evidence on CsA therapy on INS has emerged from the northern hemisphere involving mostly Caucasian children. Its use in Asian children is limited to a few studies involving small numbers. There are no studies in the published literature on the use of CsA in Sri Lankan children with INS. As per inclusion criteria of this study, patients with severe forms of SDNS who were already treated with cyclophosphamide and relapsing on very high doses of prednisolone were recruited. The results of this study reveal that the use of CsA in combination with prednisolone is effective in maintaining sustained remission in severe forms of SDNS with a significant steroid sparing effect. Biochemical evaluation revealed a significant rise in serum albumin and a significant reduction in the serum cholesterol level at six months of therapy which confirms the stability of the disease. The ability to reduce the maintenance dose of prednisolone in over $80 \%$ of patients indicates its potency as a steroid sparing agent.
Notable side effects were hypertension and hirsutism. Although the serum creatinine was significantly raised only in the 2 patients who were withdrawn from the study, this does not rule out chronic CsA nephrotoxicity which can only be documented by renal biopsy ${ }^{22}$ and most recommend a renal biopsy at the completion of 2 years of therapy.

\section{Conclusions}

- Treatment with CsA in combination with lowdose prednisolone is highly effective in maintaining complete remission in difficult SDNS in childhood.

- Side effects encountered were reversible nephrotoxicity (4\%), hypertension (57\%) and hirsutism $(80 \%)$.

- There was no significant difference in the response rate according to the different histological types. Thus a renal biopsy is not essential when commencing CsA therapy for steroid sensitive but dependent patients.

\section{References}

1. Inoue $\mathrm{Y}$, Iijima $\mathrm{K}$, Nakamura $\mathrm{H}$, Yoshikawa $\mathrm{N}$. Two-year cyclosporine treatment in children with steroid-dependent nephrotic syndrome. Pediatric Nephrology 1999; 13: 33-8. http://dx.doi.org/10.1007/s004670050558

2. Arbeitsgemeinschaft fur Pediatrische Nephrolsogie Effect of cytotoxic drugs infrequently relapsing nephrotic syndrome with or without steroid dependency. New England Journal of Medicine 1982; 306: 451-4. http://dx.doi.org/10.1056/NEJM198202253060803

3. Korbet SM, Schwartz MM, Lewis EJ. Primary focal segmental glomerulosclerosis: clinical course and response to therapy. American Journal of Kidney Diseases 1994; 23:773-83.

4. Lee KW, Mak A. An update review of therapeutic regimens for steroid resistant idiopathic nephrotic syndrome. Hong Kong Journal of Paediatrics (new series) 2000; 5:70-75.

5. Yap HK, Cheung W, Murugasu B, Sim SK, Seah CC, Jordan SC. Th1 and Th2 cytokine mRNA profiles in childhood nephrotic syndrome: evidence for increased IL-13 mRNA expression in relapse. Journal of the American Society of Nephrology 1999; 10: 529-37. 
6. Meyrier A, Simon P, Perret G, Condamin MC. CsA in lipoid nephrosis and focal-segmental hyalinosis resistant to other treatments. Proceedings of the 18th Annual Meeting of the American Society of Nephrology 1985; 48A (abstract)

7. Tejani A, Butt K, Khawar R, Suthanthiran M, Rosenthal CJ, Trachtman H, et al. Cyclosporin induced remission of relapsing nephrotic syndrome (RNS) in children. Proceedings of the 18th Annual Meeting of the American Society of Nephrology 1985; 57A (abstract)

8. Bunjes D, Hardt C, Rollinghoff M. Cyclosporin A mediated immunosuppression of primary cytotoxic T-Cell response by impairing the release of interleukin-1 and interleukin-2. European Journal of Immunology 1981; 11: 657-9. http://dx.doi.org/10.1002/eji.1830110812

9. Meyrier A. Antiproteinuric and immunological effects of cyclosporin $\mathrm{A}$ in the treatment of glomerular diseases. Nephrology Dialysis Transplantation 1992; 7(Suppl 1):80-4.

10. Savin VJ, Sharma R, Lovell HB, Welling DJ: Measurement of albumin reflection co-efficient with isolated rat glomeruli. Journal of the American Society of Nephrology 1992; 3: 1260-9.

11. Savin VJ, Sharma R, Sharma M, McCarthy ET, Swan SK, Ellis E, et al. Circulating factor associated with increased glomerular permeability to albumin in recurrent focal segmental glomerulosclerosis. New England Journal of Medicine 1996; 334: 878-83. http://dx.doi.org/10.1056/NEJM199604043341402

12. Godfrin Y, Dantal J, Perretto S, Hristea D, Legendre $\mathrm{C}$, Kreis H, et al. Study of the in-vitro effect on glomerular albumin permselectivity of serum before and after renal transplantation in focal segmental glomerulosclerosis. Transplantation 1997; 64: 1711-5. http://dx.doi.org/10.1097/00007890-199712270$\underline{00014}$

13. Singh A, Tejani C, Tejani A. One-center experience with cyclosporine in refractory nephrotic syndrome in children. Pediatric Nephrology 1999; 13(1):26-32. http://dx.doi.org/10.1007/s004670050557
14. Mowry JA, McCarthy ET. Cyclosporin in glomerular disease. Seminars in Nephrology 1996; 16(6):548-54.

15. Ponticelli C, Rizzoni G, Edefonti A, et al. A randomized trial of cyclosporin in steroid resistant idiopathic nephrotic syndrome. Kidney International 1993; 43:1377-84. http://dx.doi.org/10.1038/ki.1993.194

16. Niaudet P. Treatment of childhood steroid resistant idiopathic nephrosis with a combination of cyclosporin and prednisone. French Society of Paediatric Nephrology. Journal of Pediatrics 1994; 125:981-6.

http://dx.doi.org/10.1016/S0022-3476(05)82020-7

17. Habib R, Niaudet P. Comparison between pretreatment and post-treatment renal biopsies in children receiving cyclosporin for idiopathic nephrosis. Clinical Nephrology 1994; 42:141-4.

18. Mahmoud I, Basuni F, Sabry A, Husseini AE, Hassan N, Ahmad NS, et al. Single-centre experience with cyclosporin in 106 children with idiopathic focal segmental glomerulosclerosis. Nephrology Dialysis Transplantation 2005; 20(4):735-42.

http://dx.doi.org/10.1093/ndt/gfh766

19. Abeyagunawardena AS. Treatment of steroid sensitive nephrotic syndrome. The Indian Journal of Pediatrics 2005; 72(9):763-9. http://dx.doi.org/10.1007/BF02734149

20. Abeyagunawardena A, Dillon MJ, Rees L, van't Hoff W, Trompeter RS. The use of steroid sparing agents in steroid sensitive nephrotic syndrome Pediatric Nephrology 2003 18: 919-24. http://dx.doi.org/10.1007/s00467-003-1216-z

21. Consensus statement on management and audit potential for steroid responsive nephrotic syndrome. Report of workshop by the British Association for Paediatric Nephrology and Research Unit, Royal College of Physicians. Archives of Disease in Childhood 1994; 70:151-7. http://dx.doi.org/10.1136/adc.70.2.151

22. Gregory MJ, Smoyer WE, Sedman A, et al. Long-term cyclosporin therapy for paediatric nephrotic syndrome: a clinical and histologic analysis. Journal of the American Society of Nephrology 1996; 7(4):543-9. 